\title{
LA PEREgRINACIÓN AUTOBIOGRÁFICA DE ANASTASIO-JERÓNIMO (GRACIÁN DE LA MADRE DE DIOS)
}

\author{
M. ${ }^{a}$ Pilar Manero Sorolla \\ Universidad de Barcelona
}

Sólo dos meses más tarde de la muerte en Úbeda de san Juan de la Cruz, el 14 de diciembre de 1591, se vota en Madrid, después de un largo y triste proceso que tiene por sede el antiguo convento de san Hermenegildo, la sentencia de expulsión de la orden del Carmen de Jerónimo Gracián, el 17 de febrero de $1592^{1}$. Es el penoso ultimátum que determinará en seguida el exilio europeo y más tarde la escritura de la Peregrinación de Anastasio ${ }^{2}$ del primer provincial del Carmelo descalzo; exilio vivido y peregrinación recorrida en la realidad histórica en hábito que ya no puede ser el de carmelita, pero que Gracián querrá pobre y tosco, con el emblematismo eremítico de su antigua orden y con la dimensión de monje andariego, falto de horizonte conventual, al que le aboca su expulsión:

«[...] quítanme el hábito después de larga prisión; y sentí mucho que me pusiesen manteo y sotana de muy buen paño, que era de un novicio que había

1 Silverio De Santa Teresa, Historia del Carmen Descalzo en España, Portugal y América, Burgos, Monte Carmelo, 1937, VI, pp. 504-529, en especial.

2 La primera noticia sobre la elaboración de la obra nos la proporciona el propio Gracián en una carta fechada en Bruselas el 4 de mayo de 1609 y dirigida a su hermana, María de san José, del convento de Consuegra (Toledo): «[...] los trabajos y Peregrinación de Anastasio ya están escritos en muchos pliegos de papel, en un diálogo, que costó mucho trabajo decirlo [...]». Y, aunque su redacción última tuvo lugar en 1610, parece que se hallaba ya escrita con anterioridad, siendo 1613 la fecha de conclusión definitiva y la que consta en el ms. autógrafo de Amberes, hoy en el Carmelo Real de Bruselas: PEREGRINACIÓN DE ANASTASIO/en que se trata de los trabajos, persecuciones, peregrinaciones, y exercicios del Mastro (sic) fray Gerónimo Gracián de la Madre de Dios Carmelita, desde que tomó el hábito descalzo hasta el año 1613./Compuesto en modo de diálogo entre Anastasio y Cirilo./PP. Carmelitanorum Conventus Antuerpiensis Discalceatorum. Tomo los datos de la «Introducción» a la ed. de Giovanni Maria Bertini, Barcelona, Juan Flors, 1966, «Espirituales Españoles», serie A, tomo XVIII, p. 21. La obra fue editada por primera vez en 1902 por Ángel María DE SANTA TERESA y años más tarde por Silverio DE SANTA TERESA, Obras de fray Jerónimo Gracián, Burgos, Monte Carmelo, 1933, t. III. 
entrado, el cual buen vestido duró hasta llegar a casa de mis padres desde el convento, que luego me lo quité e hice hacer un herreruelo largo hasta los pies con un hábito de buriel, del paño más basto que se halló puesto en figura de ermitaño o peregrino» ${ }^{3}$.

No era esta sentencia la única emitida en las disposiciones de la nueva Descalcez. Las convulsiones incubadas desde antiguo en el seno de la orden, prácticamente desde 1582 , año de la muerte de santa Teresa, afloran y culminan de 1591 a $1592^{4}$, provocando la expulsión o el exilio, el encarcelamiento o la marginación de las personalidades fundamentales de la reforma teresiana. Por ello, la suerte de Gracián no puede desgajarse de la de san Juan en su último exilio andaluz de La Peñuela ${ }^{5}$, pero tampoco de la de María de san José (Salazar) ${ }^{6}$, presa en su propio convento lisboeta de san Alberto o la de Ana de Jesús (Lobera) ${ }^{7}$ cuyas circunstancias adversas en la orden, desde 1591, propician sus fundaciones en Francia y Flandes: exilio europeo, al cabo, que su grandeza convierte en proyección internacional del Carmen descalzo.

La proclamación de Nicolás de Jesús María (Doria) como segundo provincial, en el capítulo de Lisboa de 1585; la marginación y descrédito que se van tejiendo en torno al anterior y primer provincial, como consecuencia; el cambio de orientación espiritual que se opera a partir de entonces en pos de un rigorismo ascético exacerbado, que intenta recuperar antiguos planteamientos religiosos extremos ${ }^{8}$ que alejan a la orden del humanismo cristiano y místico, ideal de santa Teresa; la demasiada reglamentación y centralización, más la paulatina desfiguración de las Constituciones teresianas $^{9}$; en fin, la animadversión personal que Doria sentía por Jerónimo de la Madre de Dios como favorito de santa Teresa y de las descal-

3 Peregrinación de Anastasio, ed. cit. de Giovanni Maria BERTINI, por la que citaré la obra en lo sucesivo.

4 Para la información pormenorizada y crítica de los acontecimientos, vid. los estudios de Anselmo DONÁZAR ZAMORA, Principio y fin de una Reforma. Una revolución religiosa en tiempos de Felipe II. La Reforma del Carmen y sus hombres, Bogotá, Guadalupe, 1968; e Ildefonso MORIONES, Ana de Jesús y la herencia teresiana ¿Humanismo cristiano o rigor primitivo?, Roma, Teresianum, 1968.

5 Describen con pormenor esta última etapa de la biografía del santo, tanto Crisógono de Jesús en su clásica Vida de san Juan de la Cruz, ed. póstuma, preparada y anotada por Matías DEL NIÑo JESÚs, Madrid, BAC, 1991, pp. 359-407, como Bruno DE JÉsus MARIE, Saint Jean de la Croix, Bruges, Desclée de Brouwer, 1961, obra de la que utilizo la ed. italiana, traducción de Emilia SANTAMARíA, Milano, Ancora, 1963, pp. 447-478.

6 Vid., a este propósito, mi artículo, «Exilios y destierros en la vida y en la obra de María de Salazar», 1616, Madrid, Castalia, 1988, pp. 51-59. En general: Simeón DE LA SAGRADA FAMILIA, «Introducción» a los Escritos Espirituales de María DE SAN JOSÉ (SALAZAR), Roma, Teresianum, 1979.

7 Vid. el op. cit. de Ildefonso MORIONES, pp. 323-459, principalmente.

8 Vid. el op. cit. de Anselmo DonÁZAR, pp. 113 y ss., en especial.

9 Vid. el op. cit. de Ildefonso MORIONES, pp. 164-174 y 203-223. 
zas ${ }^{10}$; todo fue tejiendo un conflicto, hilvanado por la calumnia, que afectó al provincial y al Carmelo femenino, disminuido gradualmente del protagonismo que tuvo en la Descalcez; relegado, a partir de ahora, a una triste cuando no penosa dependencia.

Son los años de la Consulta ${ }^{11}$ y del Breve ${ }^{12}$. Doria estaba alterando la estructura original de las descalzas. En gravosa compensación, las dotaba de un consejo de hombres que había de dirigirlas, juzgarlas y asignarles superiora y confesor. Pero las grandes prioras habían convivido con Teresa de Jesús. Sabían que aquél no era su estilo. A su manera se rebelaron. Ana de Jesús había hecho reimprimir en 1588 las Constituciones de santa Teresa para que todos los conventos pudieran tenerlas a mano y para que las monjas recordasen su origen espiritual. Al año siguiente, pidió a Roma, al papa Sixto V, un breve, bien llamado Salvatoris, que salvaguardase esta herencia teresiana frente a las pretensiones de Doria. Imploró también la ayuda de los amigos de siempre: los de fuera de la orden, Teutonio de Braganza ${ }^{13}$ y Fr. Luis de León ${ }^{14}$, que podían ayudar más y que acabaron siendo verdaderos ejecutores de la petición. Recurrió también a los amigos de dentro: el primero Gracián, demasiado perseguido y calumniado para ser efectivo en su defensa; el segundo Juan de la Cruz, que, aun formando parte de la Consulta, en principio ${ }^{15}$, recapacitó luego y defendió a Gracián

10 Vid. el op. de Hipólito DE LA SAGRADA FAMILIA, «Le conflit Doria-Gatien. Étude historico-juridique», Études Carmélitaines, XXV (1946), pp. 196-273. También: Marie DE ST. JOSEPH, Le Père Gratien dans le développement de la Réforme Thérèsienne, Éditions du Carmel, Tarascon, II, 1962.

11 Vid. el op. de Efrén J. M. Montalva, La herencia teresiana, Madrid, Espiritualidad, 1975 , pp. 292 y ss.

12 Efrén J. M. MonTalva, op. cit., pp. 305 y ss.

13 La amistad y protección del arzobispo de Évora hacia la Descalcez arrancaba de los tiempos de santa Teresa, en especial de la época de escritura y publicación de la segunda redacción de Camino de perfección que, finalmente, ve la luz en Évora en 1583. Pero vid. el op. de Efrén DE LA MADRE DE DIOS y OTGER STEgGinK, Tiempo y vida de Santa Teresa, Madrid, BAC, 1977, pp. 359 y ss., 494 y 510. La dedicación al Carmen del insigne prelado se hará igualmente evidente en las fundaciones portuguesas. Vid., a este respecto, el op. de Belchior DE SANTA ANNA, Chronica dos Carmelitas Descalços do Reyno de Portugal, Lisboa, 1657, t. I, principalmente.

${ }_{14}$ La relación cordial de fray Luis y el Carmen, concretamente con Ana de Jesús, se había estrechado a raíz de la preparación y publicación de las Obras de santa Teresa en la ed. de Foquel, Salamanca, 1588; pero va a subrayarse en estos nuevos tiempos recios. Fue siempre patente, y está fuera de duda, la admiración que sintió el gran humanista por la obra fundacional y literaria de santa Teresa. Sobre este último aspecto vid. el interesante artículo de Tomás Álvarez, «Fray Luis de León y Santa Teresa. El profesor salmantino ante la monja escritora», Santa Teresa y la Literatura Mística Hispánica, Madrid, Edi, 1984, pp. 493-503.

15 Juan de la Cruz fue nombrado por Doria primer definidor y consiliario de la Consulta en el capítulo general de Madrid en 1588; por lo tanto, en un primer momento, se convirtió en delegado del nuevo provincial y en ejecutor de su política a la que 
y a las descalzas, escribiendo con ello el último capítulo de su desgracia. Porque es más que fama que sobre él, de tan grande y antigua tradición como director y confesor de monjas desde la primera experiencia en La Encarnación abulense en 1572, se tejieron las mismas habladurías y delaciones que habían afectado al primer provincial y que ambas se hallaban en un mismo proceso ${ }^{16}$. La idea de las misiones americanas, al cabo, destierro solapado, cundió como medida airosa para alejar del meollo de la dirección de la orden a dos egregias personalidades molestas; pero, en la espera, Juan de la Cruz enfermó en su provisional exilio de La Peñuela, muriendo poco después, lejos de Castilla, pero en el seno de la orden y con aureola de santo del Carmen descalzo. Gracián, conocida la sentencia de expulsión, marchó a Roma en busca de la justicia que esperaba le otorgase el pontífice, Clemente VIII.

No era esta la primera ni será la última vez que Jerónimo Gracián cruce las fronteras de su patria por imperativos de su orden y por devoción personalísima. Él mismo, a través de sus obras literarias, nos ofrece la línea documental en la que apoyar viajes y exilio. Sus diálogos, en gran parte autobiográficos ${ }^{17}$, especialmente el de Anastasio y Cirilo ${ }^{18}$, nos presentan un diseño de una etapa crucial de la historia de su vida pasada, verdadera y dolorosa odisea, servida por el arte de la memoria, desde el distanciamiento temporal de las penosas vivencias, con una finalidad ante todo autojustificativa y aclaradora de los actos y acontecimientos que protagonizó y sufrió desde 1572, fecha de su ingreso en la Descalcez, hasta 1607, año de su partida para Flandes. Sus cartas conservadas, editadas recientemente ${ }^{19}$, facilitan, por otro lado, numerosas noticias, igualmente autobiográficas, relatadas desde la inmediatez del presente de los hechos vividos y

tres años después habría de oponerse. Vid. también en este sentido, para el estudio del cambio operado en la actitud de san Juan y sus causas, el op. cit. de Anselmo DONÁZAR, pp. 107 y ss.

16 Anselmo DONÁZAR, op. cit., p. 284.

17 Diálogos de la muerte de Santa Teresa, Diálogo de un Pastor y una Pastora sobre el gobierno de cierto ganado, Diálogo del cautiverio, más numerosísimos escritos, la mayoría de ellos inéditos, desaparecidos o por localizar, pues según testimonio de Nicolás ANTONIO, en su Bibliotheca Hispana Nova, Madrid, 1783, I, p. 83 y ss., un catálogo de las obras de Gracián, dividido en cinco volúmenes, fue mandado a Roma, al Carmen de la Traspontina, a fines del siglo XVII.

18 Peregrinación de Anastasio cit. Otros diálogos inéditos, guardados en el Archivo Histórico Nacional se perfilan igualmente como autobiográficos, Diálogos sobre las persecuciones de Eliseo, Del suceso de la vida de Eliseo y su vocación, La Religión y el progreso en ella y funciones de algunas cosas, Diálogos de la Reformación. Como indica Giovanni Maria BERTINI en op. cit., p. 3, «un cotejo concienzudo permitiría afirmar si el contenido de estos diálogos está comprendido en la Peregrinación de Anastasio».

19 Por Juan Luis AstigarRagA, Roma Teresiarum, «Monumenta Historica Carmeli Teresiani», 9, 1989. 
del discurrir de acontecimientos históricos que abarcan los años de 1571 a 1614. La biografía de Andrés del Mármol ${ }^{20}$, amigo, pariente y defensor suyo en los peores años de su existencia, con la prevención que requiere cualquier biografía-hagiografía barroca, aunque sea sobria como lo es ésta, coadyuva, en un primer momento, a completar el trazo documental de su vida cosmopolita y viajera, antes que peregrina y de exiliado ${ }^{21}$.

Las fundaciones de Portugal, con posible extensión al Congo y Angola ${ }^{22}$, habían llevado a Gracián, en 1585, a Lisboa desde una Andalucía proyectada para la Reforma y para la integración en el Carmen descalzo de sus eremitorios y desiertos ${ }^{23}$, aunque no siempre considerada en el siglo XVI, desde la perspectiva de un castellano, además carmelita, como casa propia $^{24}$. Pero el cometido de Gracián en tierras lusitanas no tuvo siempre un cariz exclusivamente espiritual. Trascurría la época de anexión de Portugal al trono de los Austrias y el cardenal, archiduque Alberto, que gobernaba el reino en nombre de su tío, el rey Felipe II, y el propio monarca, le habían encomendado tareas políticas en relación a la pacificación del nuevo territorio anexionado. De hecho, el archiduque de Austria ${ }^{25}$ protegía personalmente la empresa de los descalzos ${ }^{26}$ frente a los carmelitas de la Observancia ${ }^{27}$, reducto de seguidores de Antonio, prior del $\mathrm{Crato}^{28}$, y de conspiradores ingleses que le ayudaban en sus irrenunciables aspiraciones al trono portugués. El Velho Carmo lisboeta pasaba a ser así un reducto independentista por tradición. No en balde lo había fundado en 1389 el

20 Excelencias, vida y trabajos del P. fray Jerónimo Gracián de la Madre de Dios. Recopilada de lo que escrivió del Santa Teresa de Jesús, y otras personas, Valladolid, por Francisco Fernández de Córdova, 1619. Sin embargo, según opinión de Nicolás ANTONIO, op. cit. I, p. 79 y 247, Andrés del Mármol fue sólo el editor de la obra y el P. Cristóbal Márquez O.C., el efectivo autor. Admite tal consideración Juan Luis ASTIGARRAGA, en op. cit. p. XX.

${ }_{21}$ Vid. también, actualmente, a este respecto, la «Introducción» cit. de Juan Luis Astigarraga, a la ed. de las Cartas de Gracián.

22 Vid. Silverio DE SANTA TERESA, Historia del Carmen Descalzo en España, Portugal y América, cit., pp. 300 y ss. en especial.

${ }_{23}$ Revelador resulta en este sentido el artículo de Isabelle POUTRIN, «Ascèse et désert en Espagne (1560-1600). Autour de la réforme carmelitaine», Mélanges de la casa de Velázquez, XXV (1989), pp. 145-159.

${ }_{24}$ Basta para probarlo la experiencia vivida y luego escrita de santa Teresa. Pero vid., al respecto, el op. de Pedro M. Piñero RAmírez, La Sevilla imposible de Santa Teresa, Sevilla, Biblioteca de temas sevillanos, 1982.

25 Vid. Francisco CAEIRO, O Archiduque Alberto de Austria, Vice-rei e Inquisidor Mor de Portugal, Cardenal Legado do Papa, Governador e despois Soberano dos Paises Baixos, Lisboa, Neogravura, 1961.

26 Vid. el op. cit. de Belchior DE SANTA ANNA, t. I.

27 Vid. José (PereIRA) DE SANTA ANNA, Chronica dos Carmelitas da antiga e regular observancia nestes Reinos de Portugal, quarta parte, Lisboa, Herdeiros de Antonio Pedroso Galrâo, 1745-1751.

28 P. José Castro, O Prior do Crato, Lisboa, Uniâo Gráfica, 1942. 
condestable Nuno Alvares Pereira, el que venciera a los castellanos en Aljubarrota. Todo un símbolo. Se requería, por lo tanto, de las buenas artes diplomáticas de Gracián para el óptimo entendimiento de los dos Cármenes, microcosmos del entendimiento de los dos reinos:

«A este punto vino la revolución del reino de Portugal, y Drake y don Anto-
nio con su armada sobre Lisbona: Fue esto el año de ochenta y ocho, tan
pronosticado de malos sucesos, aunque creo que todas las estrellas y sus malas
influencias se ensolvieron contra mí: porque padecí allí extrañamente, y se
forzó la suma de mis trabajos y persecuciones. Dejo aparte los cansancios de
ir a confesar a los castillos todos los presos por don Antonio, que no lo con-
fiaba el cardenal de portugueses, ni de otro castellano. El acudir a bien morir
a los soldados que ajusticiaban. El interceder con el marqués de Santa Cruz,
y después con el conde de Fuentes, para perdón de otros. El ir con recaudos
del padre fray Luis de Granada (que entonces estaba muy viejo y enfermo)
para componer cosas de almas, y así de portugueses como de castellanos» 29

Jerónimo de la Madre de Dios, como conciliador de carmelitas de antigua y nueva observancia y como mediador entre españoles y portugueses, no creo sintiese ningún extrañamiento en una Lisboa con presencia española en la tierra y en el mar. Cierto que permanecía lejos de Castilla, pero vivía en Portugal representando a su orden y a su rey. El virrey estaba de su parte. Teutonio de Braganza, arzobispo de Évora, antiguo admirador de santa Teresa y de sus libros, protegía la reforma carmelitana ${ }^{30}$. Fray Luis de Granada, posiblemente la mayor autoridad espiritual del reino $^{31}$, español al cabo, apoyaba la empresa con la que se sentía identificado desde un punto de vista religioso y cultural. Por otro lado, la descalza más afín a su ideario y a su personalidad, María de san José (Salazar), antigua priora de Sevilla, tenida por muchos como sucesora de santa Teresa, había pasado a Lisboa a fundar, justo en 1585, el Carmen de san Alberto ${ }^{32}$.

No creo que en estas circunstancias, las que grosso modo rodearon a Gracián en Lisboa, pese a los calzados y a los antoñistas, quepa hablar de exilio o de extranjería; ni siquiera de pérdida de un mundo lingüístico, cultural, paisajístico, sino más bien calificar esta experiencia de apertura

\footnotetext{
$29 \quad$ Peregrinación de Anastasio, ed. cit., p. 62.

30 Vid. nota 13.

31 Vid. el op. de M. ${ }^{a}$ Idalina RESINA RodRíGUEZ, Fray Luis de Granada y la Literatura de Espiritualidad en Portugal (1554-1632), Madrid, Universidad Pontificia de Salamanca y Fundación Universitaria Española, 1988.

32 Vid. tanto el op. cit. de Silverio DE SANTA TERESA, Historia del Carmen Descalzo..., pp. 436 y ss.; la Chronica de Portugal de Belchior DE SANTA ANNA, también cit., lib. I, cap. XXIV, como la «Introducción» de Simeón DE LA SAGRADA FAMILIA a los Escritos Espirituales de María de san José, Roma, Tipografía Políglota Vaticana, 1979, pp. 19 y ss.
} 
espacial, enriquecedora en todos los sentidos, de un hombre todavía joven, predispuesto al cosmopolitismo humano y cultural por cuna y por educación recibida; abocado a la continuidad de su relación con la realeza por tradición familiar y firme creencia en el providencialismo político representado por los Austrias. Su padre, Diego Gracián Alderete, había sido secretario de Cifra y Cruzada de Felipe II y antes del emperador Carlos, cargo que luego ha de continuar su hermano mayor, Antonio ${ }^{33}$. Lógicamente, la formación intelectual de Gracián estuvo determinada por los rasgos culturales de la corte y de la casa paterna, donde imperaba la devoción a Erasmo ${ }^{34}$, base sólida de la cultura europea, y a los clásicos greco-latinos traducidos por su padre; experiencia que más de una vez, posteriormente, se ha de traslucir en su escritura y que luego completará con el maestro Alvar Gómez de Castro y, más tarde, en Alcalá ${ }^{35}$, la universidad abierta al influjo e intercambios europeos. Por ella fue Gracián Bachiller en Filosofía y Maestro en Teología y en ella recibió la impronta profunda del ideario expansivo y universalista de la Compañía de Jesús, antes de ingresar en el Carmen descalzo en 1572, sin perder por ello el vínculo, hecho de afectos familiares e imperativos políticos, con el ambiente cortesano-humanístico en el que creció; hasta que en 1592, después de casi un año de reclusión en la madrileña cárcel conventual de san Hermenegildo, se inicie su verdadero exilio, expulsado de su orden y repudiado por su rey, atento ahora a solventar las penosas relaciones con los banqueros genoveses, en las que, ya no él, sino el nuevo provincial, Doria, podía ser, había sido ya, excelente mediador y ejecutor ${ }^{36}$ :

33 Interesante semblanza y copiosa documentación sobre la familia Gracián-Dantisco nos ofrece Margherita MORREALE en su «Introducción» al Galateo Español de Lucas GRACIÁN DANTISCO, hermano de Jerónimo de la Madre de Dios. (Madrid, CSIC, 1968, pp. 4-17). También Enrique Llamas MARTíneZ, «Jerónimo Gracián de la Madre de Dios... su familia y su ascendencia genealógica», Revista de Espiritualidad, XXXIV (1975), pp. 379-395.

34 Vid. Marcel Bataillon, Erasmo y España, Madrid, FCE, 1966, pp. 622 y ss., considera a Diego Gracián como auténtico erasmista, proporcionándonos la lista de las obras que tradujo: los Apophtemata, Moralia, algunas vidas de Plutarco, la República de los Lacedemonios, la Cinegética de Xenofonte, etc. Vid. también: Marcelino MENÉNDEZ Y PELAYO, Historia de los heterodoxos españoles, Madrid, CSIC, 1963, III, pp. 303 y ss.

35 Vid., a este propósito, el estudio de Enrique Llamas MARTíneZ, «Jerónimo Gracián Dantisco (de la Madre de Dios) en la Universidad de Alcalá (1560-1572)», Ephemerides Carmeliticae, XXVI (1975), pp. 176-212.

${ }_{36}$ Nicolás de Jesús María, genovés de origen, estaba emparentado con los Spínola, banqueros de profesión. Su propia familia, y él mismo, antes y después de ingresar en el Carmen, se hallaban igualmente dedicados a las finanzas. Pero vid. a este respecto el op. cit. de Anselmo DONÁZAR, pp. 256 y ss. También, y en general, por lo que se refiere al problema financiero en estos años, el op. de Modesto UlloA, La Hacienda real de Castilla en el reinado de Felipe II, Madrid, FUE, 1979. También: Felipe RUIZ MARTín, «La banca de España hasta 1782», El Banco de España. Una historia económica, Madrid, 1980. 
«[...] porque el padre fray Nicolás de Oria [...] estaba entonces actualmente haciendo un notable servicio al rey y a toda la cristiandad, que fue remediar los daños que venían a España de los contratos con los genoveses que, con sus cambios y recambios, se chupaban toda la moneda; y por orden suya se hizo entonces aquel decreto contra los genoveses, de que el rey estaba tan agradecido que, si él quisiera, le hiciera arzobispo y le diera todo lo que le demandara» ${ }^{37}$.

La experiencia italiana de Gracián, la nueva etapa de su vida, eminentemente romana, y que, de manera intermitente, va a durar hasta 1600 , se abre, lógicamente, con otro signo: el de la soledad, el desamparo y la persecución.

No podemos detectar tampoco aquí un problema lingüístico que, en puridad, no lo hubo. El latín, que él dominaba, era lengua de entendimiento universal entre los intelectuales de la época, en especial entre el clero, y el italiano no le era desconocido. Ni siquiera podemos advertir, por lo que él mismo nos describe y cuenta, una posible animadversión del romano hacia su persona, en su calidad de español, aunque el poderío de la corona de España fuese temido entonces en Roma y los españoles no necesariamente queridos.

Pero el problema de Gracián era de otra índole: se sentía marginado interiormente, en el ámbito de su Iglesia y de su magisterio espiritual. Pesaba sobre él una grave calumnia: relajación y trato indebido con las descalzas, que afectaba a su honor de cristiano y de carmelita. La sentencia inhumana, que pasaría a los libros de la orden ${ }^{38}$, era implacable en su desgracia. Ponía en entredicho «su manera de ser y de pensar, su pasado, su presente y su porvenir» ${ }^{39}$. Le mandaba cobijarse en otra orden que no fuese la del Carmen. Pero ¿qué orden iba a acogerle con semejante recomendación? Los repetidos fracasos a sus numerosas tentativas, que él mismo nos cuenta, parecían inevitables:

«[...] fui a los capuchinos, cartujos, franciscanos descalzos y a todas las demás religiones, a pedir su hábito; ninguno me lo quiso dar, y vine desechado de todas las órdenes como el más infame religioso que había en el mundo. Pedíales, cuando me desechaban, me diesen cédula firmada del superior de que le había pedido el hábito, y no quedaba por mí sino por ellos, que no me la querían dar» ${ }^{40}$.

37 Jerónimo Gracián, Peregrinación de Anastasio, ed. cit., pp. 76-77.

38 Guardada en el Archivo Histórico Nacional, legajo 4515, VII, 15. Hay otro ejemplar de la sentencia en el legajo 4514, XI, 11. Tomo los datos del op. cit. de Anselmo DONÁZAR, p. 203, n. 264. La edición de los documentos que se refieren al proceso de expulsión aparecerán próximamente en Monumenta Historica Carmeli Teresiani del Teresianum de Roma.

39 Anselmo DONÁZAR, op. cit., p. 150

40 Jerónimo Gracián, Peregrinación de Anastasio, ed. cit. pp. 82-83. 
De su peregrinación romana, tenemos constancia de los momentos puntuales de su itinerario. El primer paso, el recorrido a pie de las estaciones romanas «aspiración de todo peregrino» piadoso. El segundo, la búsqueda de alojamiento que el Carmen le niega. El tercero, que va a ser largo y costoso, el ruego al pontífice Clemente VIII de la revisión y revocación de la sentencia de Madrid, que Roma, en principio, le declina por orden del rey de España:

«No entendía yo este secreto, hasta que el embajador (que era el duque de
Sesa), compadeciéndose de mí, me la declaró mostrándome una carta del
rey, con palabras escritas de su misma mano que decían: si aportare ahí el
padre Gracián, pedí al Papa que no lo oigan ni se vuelva a tratar más de este
negocio» ${ }^{41}$.

Gracián no quiere desprestigiar a Felipe II, declarando las irregularidades de la sentencia de Madrid autorizada por el monarca, pero tampoco puede callar, pues está en juego su futuro como religioso. Insiste sin estridencias.

Sabido es que la justicia procede con lentitud y, a la espera del veredicto papal, viaja a Nápoles y a Palermo con el propósito de visitar a los virreyes, amigos de su familia. Como cualquier exiliado procura estrechar los lazos con los compatriotas que le aman y le pueden proteger. Pero en el viaje de vuelta, a la altura de Gaeta, unos corsarios turcos asaltan su fragata. Gracián cae prisionero. También él, como Cervantes, tendrá, entre las experiencias de su propia peregrinación, unos baños, en su caso tunecinos:

«Con todo eso esperaba que el Bajá me llamase para tratar de mi redención; mas no sucedió así sino que me llevaron al baño con los demás cristianos cautivos» ${ }^{42}$.

Será éste el contrapunto africano que luego, en 1600, habrá de repetir, una vez más, de su fundamental europeismo; además de la constatación de una realidad turca en un Mediterráneo todavía lepantino ${ }^{43}$.

Duró esta esclavitud un año y medio ${ }^{44}$, hasta 1595 . Tras su cautiverio, muerto Doria, reanuda Gracián, a sus cincuenta años, su segunda etapa italiana, esta vez marcada por el signo de la reconciliación. El papa Cle-

${ }^{41}$ Jerónimo Gracián, Peregrinación de Anastasio, ed. cit. p. 82.

42 Peregrinación de Anastasio, ed. cit., p. 94.

43 Vid. Fernand Braudel, La Méditerranée et le monde méditerranéen à l'époque de Philippe II, Paris, Armand Colin, 1966.

${ }_{44}$ Vid., en este punto, el op. de Luis RosAlES, Jerónimo Gracián de la Madre de Dios. Crónica de cautiverio y de misión, Madrid, Breviario del pensamiento español, 1942. 
mente VIII le concede finalmente el suspirado breve de la revocación de la sentencia de Madrid ${ }^{45}$ y su readmisión en el Carmen. No se trata de un paso definitivo, porque su antigua orden se mostrará reacia a admitir la decisión papal, pero sí importante en la dinámica de su futuro y en la consolidación de su asentamiento en Roma. Querido por todos: papa, cardenales, vicario general, con la simpatía de obispos y espirituales de la talla moral de Felipe Neri, el Carmen calzado de la congregación italiana tendrá a bien hacerlo de los suyos. Un eclesiástico español, el cardenal Pedro de Deza, le proporcionará el espaldarazo intelectual que, presumiblemente, también Gracián echase en falta, nombrándole teólogo para el Santo Oficio. Justo a tiempo - sea dicho de paso - para defender la ortodoxia doctrinal de Teresa de Jesús, frente a papeles provinientes de la Inquisición española que querían impedir su canonización, declarando herética su doctrina ${ }^{46}$.

No cabe duda que Gracián ha encontrado en Roma una nueva patria. ¿Cuán profundamente ha arraigado en ella? Es difícil de determinar. Porque en la vida de un religioso, la identidad espiritual con el entorno, ¿acaso no cuenta más que la nacional? Por otro lado, ahora, como en sus mejores años lisboetas, ¿no se halla Gracián próximo a compatriotas o, lo que es más importante, a seres que le comprenden y le respetan? Su profundo sentimiento del deber le determinará, sin embargo, y por encima de todo, a acatar órdenes por las que tendrá que emprender nuevos viajes, a menudo de carácter misionero o fundacional. Uno de ellos, iniciado en 1600, después de haber obtenido un segundo breve que le autoriza a viajar por donde hubiere de menester, le llevará de regreso a la patria y al hogar. Dos años antes, en 1598, Felipe II había muerto en El Escorial. Algunos días después de su llegada, morirá su madre, Juana Dantisco ${ }^{47}$. Ambas muertes me parecen significativas en su regreso:

«Estuve un poco de tiempo en San Martín in Montibus de los calzados. De ahí me mandó ir el Protector de mi Orden a casa del cardenal Deza, protector de España; servile cinco años de oficio de teólogo, escribiendo e imprimiendo libros. De los memoriales, que yo había dado al Papa, resultó que a la

45 Para más detalles, vid. el op. cit. de Juan Luis AstigarragA, pp. 26 y ss.

46 Vid. la carta del propio Gracián dirigida a su hermana Isabel de Jesús y fechada en Roma el 29 de abril de 1597, pp. 202-203 de la cit. ed. de Juan Luis AstiGARRAGA. También la p. 27 de la «Introducción» a las Cartas de Jerónimo GraCiÁN.

47 Hija natural del embajador polaco en la corte imperial. Mujer admirable, erasmista como su marido y venerada por santa Teresa, tuvo trece hijos. En relación a su familia vid. el estudio de Antonio PAZ Y MELIÁ, «El embajador polaco Juan Dantisco en la corte de Carlos V (1524-1527)», Boletín de la Real Academia Española, XI (1924), pp. 54-69, 305-320, 427-444, 586-600 y XII (1925), pp. 73-93. También, el artículo de Lorenzo RIBER, «Diego Gracián de Alderete, su familia y la Madre Teresa de Jesús», Boletín de la Academia de la Historia, XXXIV (1954), pp. 225-255. 
Congregación de Cardenales de Propaganda Fide y al Para pareció: que volviese a Africa con una comisión, que me dieron con título de ir a llevar el jubileo del Año Santo a los cristianos de aquellas partes. Vine al rey por carta para los capitanes de las fronteras, que me alcanzasen salvoconducto. Halléme a la muerte de mi madre» ${ }^{48}$.

En España, no siempre encontró Gracián un ambiente favorable. Ni en esta nueva y última estancia en la patria permaneció en ella de manera continua. Si parientes y amigos le acogieron y le agasajaron, la familia descalza tomó sus precauciones desde un primer momento; luego inauguró sus acostumbradas represalias contra él. Francisco de la Madre de Dios, el nuevo general, seguidor de la trayectoria rigorista doriana, no había olvidado las antiguas acusaciones perpetradas contra el primer provincial del Carmen. Quiere renovarlas y reavivar el «caso Gracián» y, en consecuencia, reanudar las persecuciones ${ }^{49}$. La realeza, en cambio, se mostró más favorable. Porque todo parece indicar que el nuevo rey Felipe III, como en otro tiempo hiciera su padre, aprovechó las dotes diplomáticas del carmelita para convertir misiones apostólicas, cual la predicación en el Norte de África con motivo del jubileo del Año Santo, desde noviembre de 1601 a mayo de $1602^{50}$, en misiones políticas. Y que esta relación que se inicia con el monarca se mantiene con la emperatriz María y la propia reina Margarita de Austria, que hacen de Gracián el predicador favorito de las descalzas, ya no carmelitas, sino reales. Hasta que en 1607, a instancias del archiduque Alberto, el antiguo Cardenal-Infante, virrey de Portugal, convertido desde 1598 en esposo de Isabel Clara Eugenia ${ }^{51}$ y en gobernador de los Países Bajos ${ }^{52}$, se le invita a pasar a Flandes, por formulación que le expresa personalmente el nuevo embajador, Felipe Folch de Cardona ${ }^{53}$.

Pocos meses antes, en su exilio de Dijon, tras no por silenciosa y encubierta, menos efectiva peregrinación por tierras francesas, Ana de Jesús había recibido invitación pareja de la misma archiduquesa de Austria, infanta Isabel ${ }^{54}$, particular que Gracián no desconoce. Acepta, pues, por creer

48 Peregrinación de Anastasio, ed. cit., p. 108.

49 Numerosas cartas de Gracián, analizadas por Juan Luis AstigarRagA, nos ejemplifican, documentalmente, la reacción de la Descalcez al respecto. Pero vid. el op. cit. pp. 33-38.

${ }_{50}$ Vid. Juan Luis AstigarragA, op. cit., p. 40.

51 Vid. Contesse M. DE VILLERMONT, L'Infante Isabelle, gouvernante des Pays-Bas, París, Tamines, 1912, 2 vols.

52 Vid. nota . $^{\circ} 25$.

53 Vid. el op. cit. de Juan Luis Astigarraga, p. 48.

54 La carta que la «Serenísima Infanta escribió a la venerable Madre Ana en razón de su partida a Flandes», fechada en Bruselas, el día de Santo Domingo de 1606, se conserva en el «Carmel Royal» de la capital belga, además de haberse publicado en la antigua biografía sobre Ana de Jesús, compuesta por Ángel MANRIQUE, La V.M. Ana de Jesús, discípula y compañera de la S.M. Teresa de Jesús y principal aumento de su orden. Fundadora de Francia y Flandes, Bruselas, En casa de Lucas de Meerbleck, 1632, Lib. VI, Cap. XIII, pp. 65-66. 
la medida oportuna, aunque, antes de su determinación, el nuncio haya extendido ya el breve mandándole pasar a Flandes. Se barrunta que su misión, como en los viejos tiempos lisboetas, va a ser, a la vez, apostólica y política. Viajará con la propia familia del embajador ${ }^{55}$. Sólo que ahora el peregrino tiene sesenta y dos años y ya no regresará más a la patria:

«Los religiosos [dice Gracián a este propósito] somos de manera que nunca nos deja Dios holgar mientras vivimos ni estar donde queremos» ${ }^{56}$.

Entre las razones personales que mueven a Jerónimo Gracián de la Madre de Dios a marchar a Flandes, y que él mismo razona para la ocasión $^{57}$, hay dos que me parecen determinantes. La defensa de la fe contra los herejes, la primera, con implicación de la idea de martirio, consustancial al sentimiento de la orden y tema literario de más de un carmelita, comenzando por la propia santa Teresa ${ }^{58}$. La segunda, su deseo de escribir, pulir, redondear, imprimir en varias lenguas, y distribuir una obra literaria que, iniciada en España muchos años antes y continuada en Roma, va a revisar y publicar en muy buena parte en Bruselas al final de su existencia.

De entre los numerosos escritos conservados de Jerónimo Gracián ${ }^{59}$, el mayor número, como es natural, posee carácter doctrinal o teológico ${ }^{60}$. Varios, los primeros, redactados antes de su exilio, glosan la vida y la muerte de Teresa de Jesús ${ }^{61}$, o trazan las crónicas fundacionales de los carmelitas descalzos ${ }^{62}$. Son estos escritos, fundamentalmente, los que Gracián quiere imprimir en Flandes en varias lenguas: latín, español, italiano

55 Vid. el op. cit. de Juan Luis AstigarRagA, p. 50.48.

56 Carta dirigida a su hermana María de san José, fechada en Valencia el 31 de enero de 1607. Cartas, ed. cit., p. 386.

57 Carta común que escribe a sus amigos, fechada en Pamplona, fines de mayo de 1607. Cartas, ed. cit., p. 388 .

58 Vid., entre otros escritos, el cap. I de Camino de Perfección.

59 Muchos de ellos guardados en el Archivo Histórico Nacional de Madrid, legajos 3820 y 3821 de la sección Clero. Tomo los datos de Juan Luis AstigarRagA, op. cit., p. 5.

60 Él mismo nos ofrece una lista en el diálogo XII de su Peregrinación de Anastasio, «En que Anastasio da cuenta de sus estudios y de los libros que ha escrito, de los cuales algunos ha impreso y sacado a la luz, otros están a punto para poderse imprimir, sin otros muchos papeles y tratados, que no convienen que se impriman, declarando en esto el número de las doce estrellas de la corona que están sobre el escudo», pp. 163-169 de la ed. cit.

${ }_{61}$ Tránsito y última jornada de Ángela (1583), los cit. Diálogos del tránsito de la M. Teresa de Jesús (1584) y las Escolias a la Vida de santa Teresa compuesta por el P. Ribera (1590).

62 Tema que también tratan, de manera resumida, los diálogos XIII y XIV de la propia Peregrinación de Anastasio, pp. 163-210. Vid., también, Monumenta Histórica Carmeli Teresiani cit., n. ${ }^{\circ} 3$, pp. 653 y ss. 
y francés; lenguas idóneas en la época para que una obra llegue al Occidente culto de credo católico: un plurilingüismo que, de alguna manera, lleva implícito el cosmopolitismo en el que se educó y que el exilio potencia hacia una apertura espiritual de objetivo universal, sólo recortado por la frontera impuesta por el mundo católico y por lo que bien pudiéramos llamar su tridentinismo combativo - acaso viejo influjo ignaciano- ${ }^{63}$ que justo en Flandes se hará manifiesto. En parte, esta manifestación de su ideario y de su fe se constituirá internamente en un drama de incomprensión, estrictamente humano, que añade a su sentimiento de extrañamiento frente al flamenco, en una atmósfera hostil de rebelión contra España ${ }^{64}$, una segunda distancia, infinitamente más abismal, frente al flamenco luterano.

En sus cartas, redactadas en gran parte fuera de España y de valor incalculable, no sólo por ser «la historia personal de un carmelita dentro del contexto de su propia familia religiosa, sino, asimismo, por la visión panorámica que ofrece de la historia eclesiástico-política de la Europa de finales del siglo XVI y principios del XVII» ${ }^{65}$, se trasluce ese sentimiento y limitación. Pero, al mismo tiempo, se evidencia la superación del hecho puramente personal por la preocupación e interpretación del curso de la historia.

En sus diálogos, sin lugar a dudas los primeros diálogos de carmelitas, aparece un idéntico corolario y predisposición. La peregrinación de Anastasio, semejante a una novela bizantina pero verdadera confesión existencial que concluye en Bruselas, trasciende igualmente su mera autobiografía. La narración de numerosos aconteceres y peripecias, de largos y continuos viajes del protagonista por un espacio geográfico amplio y múltiple, el propio y real recorrido por el autor; la presencia de la dinámica y el ritual de una peregrinación que se anuncia en el título y que en el libro se manifiesta como lucha y humillación continua, como huida de una persecución soterrada y búsqueda, a un tiempo, de la recuperación de un estado ideal perdido, persiguen, ante todo, la rehabilitación del protagonistaautor como religioso del Carmen, la reconsagración eclesial de su mejor manera de ser. También en este caso podemos hablar de un yo trascendido, como trascendida aparece su circunstancia. Porque, una vez rehabilita-

63 Gracián tuvo el propósito de ingresar en la Compañía de Jesús y su espiritualidad estuvo conformada por los Ejercicios Espirituales ignacianos, tanto como su apostolado por la huella de Ignacio de Loyola. Subraya el influjo ignaciano de Jerónimo de la Madre de Dios, Crisógono DE Jesús SACRAMENTADO, La escuela mística carmelitana, Madrid-Ávila, 1930, pp. 132 y ss.

${ }_{64}$ Vid., al respecto, la fundamental obra de Geoffrey PARKER, The army of Flanders and the Spanish road, 1567-1659, Cambridge University Press, 1972. Traducción española: El ejército de Flandes y el camino español, Madrid, Revista de Occidente, 1976.

65 Juan Luis ASTIGARRAGA, ed. cit., p. 3. 
do y dignificado en la realidad histórica, una vez alcanzada la gracia y la justicia, Gracián se inclina hacia la narración de la grandeza y gloria de la orden del Carmen en su propia historia de exiliado y de peregrino. Así, si los siete primeros diálogos cuentan las persecuciones, viajes y fatigas de Anastasio-Jerónimo, los siete siguientes hablan de la grandeza de la orden, pero también de los trabajos padecidos por la comunidad y las fundaciones realizadas ${ }^{66}$. Mientras que los dos últimos se constituyen en un tratado de oración y descripción de mercedes místicas: experiencia y vida espiritual del autor, servida en forma dialógica y con pacto autobiográfico ${ }^{67}$.

No registramos en esta obra tardía pérdida alguna de conciencia ni de memoria linguística por parte del autor. La extranjería y el distanciamiento consiguiente del idioma patrio y el contacto con otros diferentes no afectaron a una personalidad culta como lo fue Gracián, ni mermaron su dominio y pureza idiomáticos. Parece, de todas formas, que no llegó a dominar el francés ni a entender el flamenco. Hay un testimonio de una carta suya fechada en Bruselas, el 28 de diciembre de 1612, y dirigida a Alfonso de Narváez, bastante elocuente en este sentido:

«Mi vida es como heremítica, en unas celdas de la huerta deste convento de Calçados de Bruselas, que como ellos ${ }^{68}$ son flamencos, para mí son como pintados en tapiz» ${ }^{69}$.

Aislamiento, pues, el que vive en Flandes, jalonado con la atención apostólica de la que pudiéramos llamar colonia española, que es nutrida por lo que deducimos de la dedicatoria de un libro suyo al cardenal Bernardo de Rojas Sandoval ${ }^{70}$ :

«Mis ocupaciones, ilustrísimo Señor, en estos países, son el púlpito y confesionario, que no falta, así de los cortesanos y soldados, como de otros naturales de este mismo país, quien entienda nuestra lengua y pueda aprovechar su alma» ${ }^{71}$.

Es fama, además de hecho comprobable, que el caballero franco-español, Jean de Brétigny ${ }^{72}$, tan identificado con la obra teresiana, traductor de

66 Vid. nota $n .^{\circ} 60$.

67 Me refiero al «Pacte autobiographique» de Philippe LEJEUNE, Poétique, 6 (1973), pp. 137-162, ahora en el libro del mismo título, París, Seuil, 1975.

68 Se refiere a los frailes flamencos.

69 Cartas, ed. cit., p. 550 .

70 Sobre este notable personaje, famoso mecenas, vid. el artículo de José GoÑI GazTAMBIDE, «El cardenal Bernardo de Rojas y Sandoval, protector de Cervantes», Hispania Sacra, XXXII (1980), pp. 125-191.

71 Diez lamentaciones, Bruselas, 1611. Citado por Juan Luis AstigarRAGA, op. cit., p. 514.

72 Vid. sobre esta primordial figura en la expansión del Carmen descalzo por Europa, el op. de Pierre SÉRouet, Jean de Brétigny (1556-1634). Aux origines du Carmel de France, de Belgique et du Congo, Université de Louvain, 1974. 
la misma al francés, auxilió a Gracián lingüísticamente en Flandes y en sus viajes a Alemania, país que nuestro peregrino visitó en su programa de lucha contra el luteranismo. La amistad venía de antiguo. Brétigny en 1585 había acompañado a la comitiva que de Sevilla salió hacia Lisboa para fundar el carmelo de san Alberto. En ella figuraba Jerónimo de la Madre de Dios. Veintidós años después, acompaña a Ana de Jesús desde París a Bruselas con idéntico objetivo y, poco después, en 1611, facilita el traslado de Ana de san Bartolomé desde París a Mons. Por vías distintas, pero siempre escoltados por este, como Francisco de Salcedo, admirable caballero santo, los más directos y entrañables colaboradores de santa Teresa, que no habían muerto, se daban cita en Flandes.

Pero Brétigny ayudó sobre todo lingüísticamente a Gracián en su empresa editorial. Adelantamos ya que, desde un punto de vista personal, esta empresa se configura, aparentemente, como la primordial que tiene pensado desarrollar en los Países Bajos, tanto por las facilidades, garantías y calidad de impresión que Flandes le ofrece como, creemos, por la libertad de jurisdicción eclesial de que goza respecto del Carmen descalzo español, para mandar imprimir algunos libros no deseados por éste. En una carta familiar y, por esto mismo, suponemos que sincera, dirigida a su hermana Juliana, fechada en Bruselas en 1607, nos aclara a este propósito:

«Víneme a apear al monasterio del Carmen de los Calzados, donde estoy
entendiendo en lo principal a que vine, que es imprimir mis obras, que hay
en estas tierras mayor comodidad que en ninguna parte; y como tengo tanto
que hacer en esto y en otros negocios graves que acá se ofrecen, pienso
meterme poco en casas de frailes y monjas, sino cuando mucho predicarles
algunas veces y animar a que los Descalzos vengan» ${ }^{73}$.

Gran parte de esta labor se dirige a combatir la invasión de la «herejía» luterana y calvinista ${ }^{74}$. Aunque no deje de ser consciente de sus limitaciones, es sorprendente la red de conexiones que Gracián establece para que sus publicaciones católicas lleguen a España y a Indias. Como, asimismo, maravilla las fuentes de información que crea para localizar, desde un punto de vista editorial, las infiltraciones protestantes en Holanda, procedentes de Inglaterra, o de Alemania, a través de la feria del libro de Frankfurt ${ }^{75}$. Atento permanece, también, en la publicación y difusión de la

73 Cartas, ed. cit., pp. 403-404.

74 En este sentido, como en general para el cometido intelectual y posición espiritual-doctrinal de Gracián en Flandes, resulta esclarecedor el clásico estudio de Jean ORCIBAL, La rencontre du Carmel théresien avec les mystiques du Nord, París, PUF, 1959, pp. 18-42.

75 Estudiadas por Juan Luis AstigARRAGA en op. cit. pp. 55 y ss. y cuya información suministra algunas de las cartas de Gracián, como la dirigida al nuncio apostólico en Flandes, Guido Bentivoglio, fechadas en Bruselas en junio-julio de 1609. Vid. ed. cit., pp. 443 y ss. 
obra teresiana que se completa en 1610 con la primera edición del Libro de las Fundaciones en la casa de Roger Velpio, a instancias de Ana de Jesús y del propio Gracián ${ }^{76}$. Era el libro de santa Teresa que faltaba en la edición salmantina de Foquel, de 1588. Seguramente no convino entonces que la obra apareciese al público por el protagonismo que en ella tenían personajes tan fundamentales en la reforma descalza como Juan de la Cruz y María de san José, ya desaparecidos, o como el propio Gracián y Ana de Jesús, caídos en desgracia. Y en desgracia cayó igualmente en España este libro que, aun con sus fallos de edición, supresiones, retoques y notas del propio Gracián ${ }^{77}$, evidenciaba, desde Flandes, una verdad demasiado molesta para la Descalcez española, al recordar los orígenes de la reforma teresiana y poner de relieve a las personalidades que secundaron a santa Teresa en su indiscutible papel principal.

Pese a estas y a otras relaciones con las descalzas españolas, principalmente con Ana de Jesús y Ana de san Bartolomé, con motivo de la lógica asistencia espiritual dispensada por el antiguo provincial a las distintas fundaciones flamencas ${ }^{78} \mathrm{y}$, en especial, por la gran empresa que él promueve y a todas participa: la beatificación y canonización de santa Tere$\mathrm{sa}^{79}$, Gracián se mantuvo alejado físicamente de ellas; a la defensiva de cualquier calumnia que pudiera afectar a su persona o a las propias monjas, en un prudente y solitario distanciamiento.

En el carmelo calzado de Bruselas, monasterio medieval fundado en 1249 y clausurado en 1756, que en el tiempo que lo habitó Gracián aún acogía, pese a la persecución sufrida, entre 1578-1581, por la introducción de la doctrina luterana, a más de treinta frailes, se había instalado en el fondo del jardín, en una ermita rodeada de las brumas del Norte, que convirtió, por transformación de atmósfera vital y paisaje perdidos, en su yermo de contemplativo. Porque, a pesar de sus grandes dotes para la política y para la diplomacia, siempre al servicio de la Casa de Austria, y del jesuitismo combativo y contrarreformístico que fundamentó su sentimiento religioso y, emergiendo, le impulsaba a mezclarse en el mundo, en defensa de la Iglesia, Jerónimo de la Madre de Dios perteneció a la misma orden

${ }^{76}$ Ya como editor, traductor o biógrafo. Vid., al respecto, el clásico estudio de Alphonse VERMEYLEN, Sainte Thérèse en France au XVII siècle 1600-1660, Publications Universitaires de Louvain, 1958, p. 58. Pero, sobre todo, las propias cartas de Gracián: Números 185, 186, 193, 194, 196, 200, por ej., de la ed. cit., donde se nos da noticia de diversas publicaciones teresianas en Flandes.

77 Vid. en este sentido la «Introducción» al Libro de las Fundaciones de Santa Teresa de la ed. de Efrén DE LA MADRE DE Dios y Otger StegGinK, Madrid, BAC, 1974, p. 519.

78 Vid., al respecto, el op. cit. de Juan Luis AstigarRAGA, pp. 65 y ss.

79 Alude a ello el propio Gracián en sus cartas 164, 172 y 231 de la ed. cit., en fechas que van de 1607 a 1614 . 
de desasimiento y silencio que san Juan de la Cruz. A ella seguía conformando, también en Bruselas, su vida íntima:

«Y yo me hallo bien a mis solas en mi celda de una huerta, donde paso mi vida heremítica hasta ora de comer, que vengo acá a los negocios que duran hasta la tarde, que me buelvo a mi hermo, ocupando lo más del tiempo que puedo en oración para acabar la vida, que espero en Dios será este año [...]» ${ }^{80}$.

En realidad, morirá seis años después, en 1614: todavía a tiempo de escribir un Arte de bien morir, en que trata de las reglas, apercibimientos, exercicios, devociones, industrias, suffragios y avisos provechosos para la buena muerte ${ }^{81}$, habiendo superado, con sincretismo de buen humanista y acopio de infinita caridad cristiana, antiguas luchas de calzados y descalzos y conciliado la tradición antigua del Carmen de anacoretas con las exigencias apostólicas que le imponía él mundo moderno y su vocación de escritor. En un jardín cercado, en el centro de una ciudad gris, su propia Peñuela en la Europa del Norte, Gracián había sabido asumir el sentido sanjuaniano de la soledad en su valor y dimensión casi sacramental.

${ }^{80}$ Carta a Juliana de la Madre de Dios, fechada en Bruselas el 26 de julio de 1608, ed. cit., p. 410 .

${ }^{81}$ La obra se editó en Bruselas, en casa de Roger Velpio y Huberto Antonio, año de 1614, esta vez, sí, año de su propia muerte. 